\title{
1029 Agreement of left ventricular mass in steady state free precession (ssfp) and delayed enhancement (DE) MR images: implications for quantification of fibrosis in congenital and ischemic heart disease \\ Sigurdur S Stephensen*1, Marcus Carlsson ${ }^{2}$, Peter Munkhammar ${ }^{3}$ and Hakan Arheden ${ }^{2}$
}

Address: ${ }^{1}$ Department of Pediatric Cardiology and Department of Clinical Physiology, Lund University Hospital, Lund, Sweden, ${ }^{2}$ Department of Clinical Physiology, Lund University Hospital, Lund, Sweden and ${ }^{3}$ Department of Pediatric Cardiology, Lund University Hospital, Lund, Sweden

* Corresponding author

from I th Annual SCMR Scientific Sessions

Los Angeles, CA, USA. I-3 February 2008

Published: 22 October 2008

Journal of Cardiovascular Magnetic Resonance 2008, I0(Suppl I):AI54 doi:I0.I I86/I532-429X-10-SI-AI54

This abstract is available from: http://jcmr-online.com/content/I0/SI/AI54

(c) 2008 Stephensen et al; licensee BioMed Central Ltd.

\section{Introduction}

Visualization of fibrosis is important since it aids in diagnosis, treatment and prognosis. MRI is being established as the reference method for detection of fibrosis, myocardial infarction and quantification of left ventricular mass (LVM) both in the clinical setting and in clinical trials. The percentage of infarcted myocardium of the left ventricle is increasingly being used in clinical reports as well as preclinical and clinical trials. Delineation of fibrosis is carried out in delayed enhancement images where normal myocardium is black and fibrosis is white (Figure 1). Quantification of total left ventricular mass (LVM) can be carried out by delineating endo- and epicardium in steady state free precession (ssfp) cine images, but also in the delayed enhancement images. However, the DE sequence differ from the ssfp, which makes it possible that the quantification of volumes (e.g. LVM) may differ. It is important that the two different image sequences are comparable for determination of total amount of myocardium in order to express fibrosis as a percentage of total myocardium. This is of specific importance in patients with congenital heart disease because differentiation between myocardium and other structures such as connective tissue, scar, fibrosis and implanted structures may be difficult. To be able to use both balanced sequences and delayed enhancement images for determination of total amount of myocardium would therefore be beneficial.

\section{Purpose}

The aim of the present study was to assess the agreement of determination of left ventricular mass between cine images acquired with ssfp and delayed enhancement images, and to see if they may be used interchangeably.

\section{Methods}

Cine ssfp and delayed enhancement images were aquired in 31 patients; 10 with no signs of fibrosis, 10 with ischemic heart disease and subendocardial fibrosis typical of infarction and 11 children with congenital heart disease but without signs of fibrosis in the left ventricle. Endo- and epicardium of the left ventricle was outlined in the ssfp images as well as the delayed contrast enhancement images.

\section{Results}

Myocardial mass measured with ssfp images (126 $\pm 43 \mathrm{~g}$, range 53-220 g) was significantly higher compared to delayed enhancement images ( $117 \pm 44 \mathrm{~g}$, range 42-201 $\mathrm{g}, \mathrm{p}<0.0001)$. Balanced cine images yielded $7,7 \%$ higher values of LV mass. The difference in LVM between ssfp and DE images remained if the 10 patients with infarcts were 


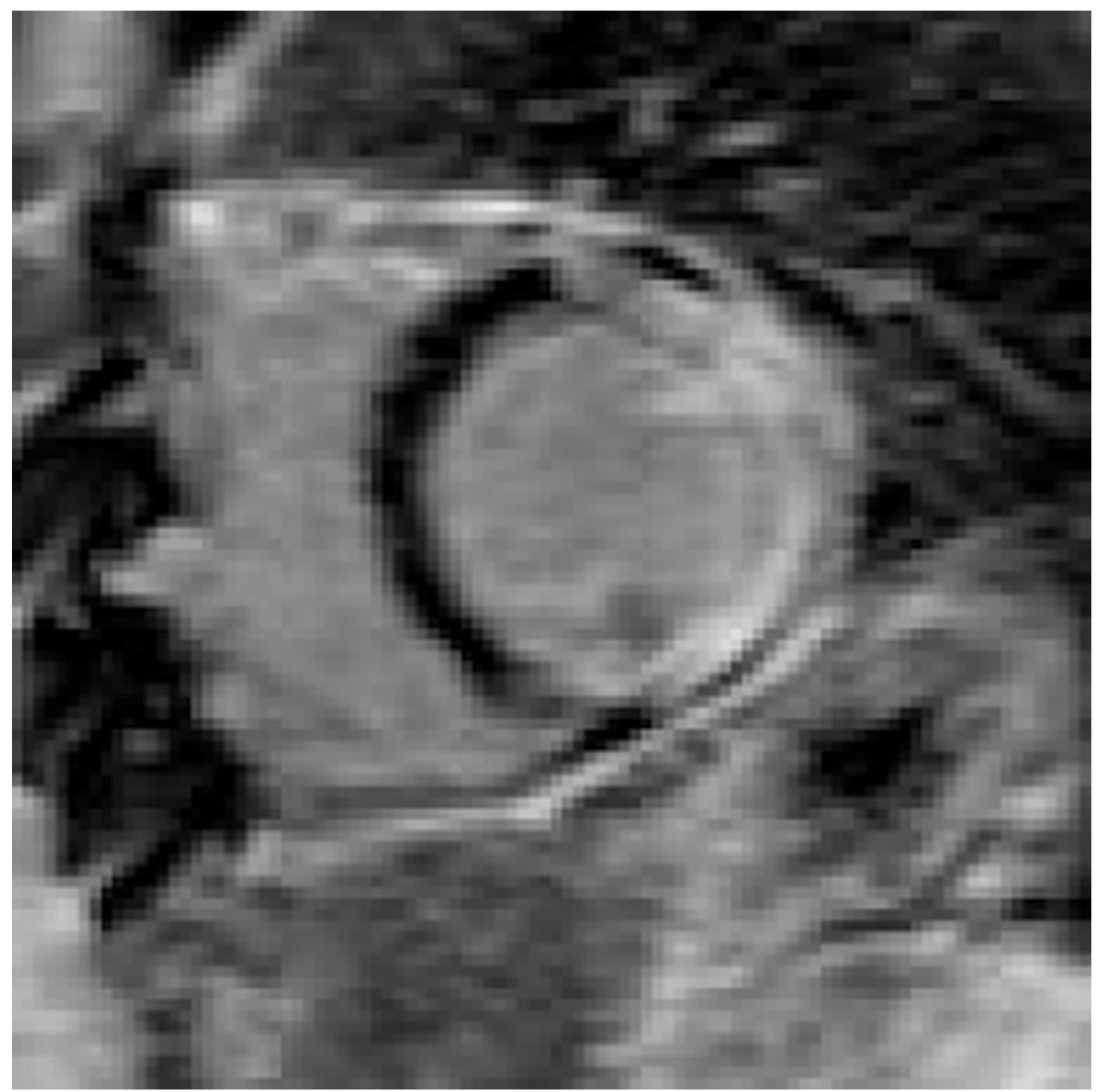

\section{Figure I}

The global hyperenhanced region assessed by ex vivo DE-MRI is consistently larger than infarct size determined by TTC in the acute phase of reperfused ischemic myocardial injury. Thus, DE-MRI may overestimate myocardial infarct size in the acute phase.

excluded $(111 \pm 38 \mathrm{~g}$ vs $101 \pm 41 \mathrm{~g}$ respectively, $\mathrm{p}<$ $0.0001)$. The difference in LVM for the two image sequences was $6,3 \%$.

\section{Conclusion}

Left ventricular mass is larger when measured with ssfp cine sequences than with DE sequences. Thus, the propor- 
tion of fibrosis of the LVM will differ by $6-8 \%$ depending if ssfp images or DE images are used to determine LVM. Therefore, a consensus statement regarding what sequences to be used, when determining the percentage of infarcted myocardium, is needed.

Publish with Bio Med Central and every scientist can read your work free of charge

"BioMed Central will be the most significant development for disseminating the results of biomedical research in our lifetime. " Sir Paul Nurse, Cancer Research UK

Your research papers will be:

- available free of charge to the entire biomedical community

- peer reviewed and published immediately upon acceptance

- cited in PubMed and archived on PubMed Central

- yours - you keep the copyright

Submit your manuscript here:

http://www.biomedcentral.com/info/publishing_adv.asp 